CARTA AL DIRECTOR

\title{
Autoamputación de la extremidad superior en un caso con esquizofrenia
}

\author{
T. Kobayashi, T. Osawa y S. Kato \\ Departamento de Psiquiatria, Facultad de Medicina de Jichi, 3311-1 Yakushiji, Minamikawachi, Tochigi 329- \\ 0498 Japón.
}

Sr. Director:

Presentamos un caso con esquizofrenia que se cortó la mano izquierda mientras estaba en tratamiento con risperidona. Aunque cortarse la muñeca es común en la práctica psiquiátrica, se ha informado sólo de 13 casos de amputación autoinfligida de extremidades superiores [2].

Un hombre de 29 años con una historia de 12 años de esquizofrenia crónica que estuvo autista y abúlico durante 10 años cambió de médico. Su nuevo facultativo intentó utilizar nemonaprida (una benzamida sustituida disponible como neuroléptico en Japón) en una dosis de $60 \mathrm{mg} /$ día para mejorar su abulia, pero sin efecto. Se añadió entonces risperidona ( $4 \mathrm{mg} /$ día) a la nemonaprida. Una semana después de la iniciación de la risperidona, el paciente comenzó a salir de la cama y se volvió activo, ayudando a sus padres en el trabajo de la casa y en el negocio familiar. Parecía alegre y expresivo. Sin embargo, tres semanas después de la iniciación de la risperidona, se cortó repentinamente la mano izquierda con un cuchillo de fruta. El cuchillo desgarró la cápsula articular de la muñeca, dejando la mano izquierda conectada apenas al brazo por la epidermis. Fue llevado al Servicio de Urgencias Médicas del Hospital de la Facultad de Medicina de Jichi. La reimplantación de la mano izquierda se abandonó porque la cápsula articular de la muñeca estaba gravemente destruida, y se llevó a cabo la amputación.
El día siguiente, se trasladó al paciente a la sala psiquiátrica. Su recuerdo de las razones que llevaron al accidente eran vagos; a veces decía que había querido morir o que voces alucinatorias le habían dicho que muriera. En otras ocasiones, no sabía por qué se había cortado la mano o decía que había querido cortar una parte excedente. Mostraba autismo, abulia, risa compulsiva, alucinaciones auditivas y perturbaciones del pensamiento. Se interrumpió la risperidona y se administró timiperona (una butirofenona derivada disponible en Japón) en dosis de $30 \mathrm{mg} /$ día, pero con un efecto limitado. Se trasladó al paciente a un hospital psiquiátrico y sus síntomas negativos graves e ideas esporádicas de suicidio le obligan a permanecer allí.

Aunque los cortes de la muñeca generalmente pretenden la muerte por desangramiento, el comportamiento presentado por el paciente era demasiado destructivo para este propósito. Tenía esquizofrenia crónica con síntomas negativos prominentes. Después que el tratamiento con nemonaprida fracasara, el tratamiento con risperidona consiguió mejorar los síntomas negativos, y se volvió activo en el trabajo diario. Sin embargo, se realizó un comportamiento autodestructivo violento mientras estaba en un posible estado delirante-alucinatorio brusco que el paciente sólo podía recordar después ambiguamente. Este comportamiento sin propósito implica diversamente intento de suicidio, obediencia a órdenes imperiosas y cortar un excedente. Especialmente, la tercera causa parece 
ser una de las características de la automutilación esquizofrénica [1].

No se puede negar que la risperidona tuvo cierta influencia en la autoamputación. Aún así, la relación entre la risperidona y la autoamputación es dudosa.

\section{BIBLIOGRAFÍA}

1 Kato $\mathrm{S}$. Thème de la mort et de la coupure chez les schizophrènes. Évol. Psychiatr. 1993;58:727-42.

2 Schlozman SC. Upper-extremity self-amputation and replantation: 2 case report and a review of the literature. Clin Psychiatry 1990;59:681-6. 